\title{
Aplicação de ferramenta proativa para análise de risco na prevenção de incêndio
}

Autores: Monica Morgese Alves, Marcia Maria Vila Real, Juliana Silveira Rodrigues Gonçalo.

\section{Sobre a instituição}

A BP - A Beneficência Portuguesa de São Paulo é um polo de saúde composto por 4 hospitais e 3 outros serviços de saúde e de educação e pesquisa. Fundada em 1859, a BP possui 8.000 colaboradores, 4.500 médicos cadastrados e oferece serviços de saúde privados e para clientes encaminhados via regulação pelo Sistema Único de Saúde (SUS).

\section{Introdução}

Os hospitais devem estar sempre vigilantes quanto às medidas preventivas para incêndio, uma vez que tal risco é sempre presente no hospital. As diretrizes de prevenção, detecção precoce, supressão, combate e saída segura das instalações de incêndio dentro do ambiente hospitalar tem como objetivo garantir que todos os ocupantes estejam protegidos contra fogo e fumaça e outras emergências das instalações. Com base nessa premissa, identificamos a necessidade de avaliar esse processo através de uma ferramenta de análise prospectiva - FMEA (Failure Mode and Effect Analysis).

\section{Objetivo}

Estabelecer preventivamente planos de melhoria no processo de prevenção de incêndio no ambiente hospitalar, após a utilização da ferramenta FMEA.
Com a aplicação da ferramenta foi calculado o risco inicial para cada etapa: Projeto Técnico/ Projeto Conceito: 132; Concorrência (contrato): 8; Entrega/ Comissionamento da Obra: 83; Operação Sistema: 2505; Treinamento: 91; Simulados: 286. As principais falhas identificadas foram: manuseio do sistema, fragilidade na central de alarmes, falta de adesão aos treinamentos e falha de comunicação pela central de segurança. Conforme as implantações de melhorias foram sendo concluída a matriz de risco foi aplicada por mais 1 vez vezes observando ao final uma redução do índice de risco nas etapas de: Operação do Sistema: 68\%, Treinamento: 65\% e Simulados: 68\%.

As ações que proporcionaram maior impacto na redução de risco foram: instalação do aviso sonoro e visual na central de monitoramento de alarmes, contratação de empresa especializada para manutenção do sistema de alarme de incêndio, tradução das funções do painel da central de alarme de incêndio e monitoramento dos treinamentos.

\section{Conclusão}

\section{Metodologia}

A análise foi conduzida pela equipe

multiprofissional do hospital avaliando os modos de

falha nas etapas que contemplam desde a

elaboração do projeto técnico até a realização de

simulados. Por meio da matriz de severidade $x$

ocorrência $x$ detecção identificou-se o risco inicial de cada etapa para implantação de melhorias para redução do risco. 